\title{
Effect of telechelic ionic groups on the dispersion of organically modified clays in bisphenol A polycarbonate nanocomposites by in-situ polymerization using activated carbonates
}

\author{
M. Colonna*, F. Acquasanta, C. Gioia, A. Celli \\ DICAM, University of Bologna, Via Terracini 28, 40131 Bologna, Italy
}

Received 12 October 2016; accepted in revised form 10 January 2017

\begin{abstract}
Nanocomposites of bisphenol A polycarbonate with organically modified clays have been prepared for the first time by in-situ polymerization using bis(methyl salicyl) carbonate as activated carbonate. The use of the activated carbonate permits to conduct the polymerization reaction at lower temperature and with shorter polymerization time with respect to those necessary for traditional melt methods that uses diphenyl carbonate, affording a nanocomposite with improved color. Moreover, an imidazolium salt with two long alkyl chains has been used to modify the montmorillonite, providing an organically modified clay with high thermal stability and wide $d$-spacing. The addition of ionic groups at the end of the polymer chain increases the interaction between the clay surface and the polymer producing a better dispersion of the clay. The presence of the clay increases the thermal stability of the polymer.
\end{abstract}

Keywords: nanocomposites, clay, imidazolium salt, bisphenol A polycarbonate

\section{Introduction}

Polymer layered nanocomposites (polymeric matrixes filled with particles that have one of their dimension in the nanometer range) $[1,2]$ often have superior physical and mechanical properties over their microcomposites counterparts, including improved modulus [3], reduced gas permeability [4], increased flame retardantcy [5, 6] and lower thermal expansion [7]. A considerable amount of the work in this area has been focused on polymeric nanocomposites containing layered silicates such as montmorillonite clay (MMT) [8-10].

A large number of papers have reported the preparation of well-exfoliated polymer/clay nanocomposites [9-14]. However, several problems have been encountered in the preparation of bisphenol A polycarbonate (PC) nanocomposites. For example, Paul
[15] reports that only a small fraction of the clay platelets are exfoliated while the main part of the $\mathrm{PC} /$ clay composites has an intercalated morphology. The reason of this low degree of dispersion has been ascribed to the poor compatibility between the clay surface and the polymer. Moreover, the PC/clay composites prepared by melt blending of $\mathrm{PC}$ with montmorillonite modified with ammonium clays [15] are always dark colored and the molecular weight of the PC matrix consistently (30-40\%) drops after extrusion. This issue has been ascribed to the use of ammonium salts for the modification of the clay (which are used in order to increase its compatibility of the clay with the polymer matrix).Indeed, ammonium modified clays are not stable in the standard polycondensation and processing conditions of PC that can exceed $300^{\circ} \mathrm{C}$. The degradation of the ammonium

*Corresponding author, e-mail: martino.colonna@unibo.it (C) BME-PT 
modified organoclay generates reactive radicals through a Hoffmann elimination reaction that causes the degradation of the PC chain through Fries rearrangement reactions [16]. These rearrangements generally give rise to quinoid moieties that are intensively colored [17].

Polycarbonate is an amorphous engineering thermoplastic that possess high mechanical properties [18, 19], stiffness and modulus, combined with outstanding impact resistance and transparency [20,21]. It is clear that the improvement in the properties of polycarbonate by the addition of the clay must be achieved without compromising its optical transparency and color in order to maintain most of its commercial applications. However, the incomplete dispersion of the clay platelets, combined with the discoloration due to degradation reactions, create several problems in obtaining a clear and transparent material.

Recently, a few papers have reported improved processes for the preparation of PC/clay nanocomposites. In particular, Rama and Swaminathan [22] have used phosphonium and imidazolium modified organoclay to prepare $\mathrm{PC} /$ clay nanocomposites by in-situ melt polycondensation. However, even using thermally stable organoclays they have obtained a dark brown material. Huang et al. [23] reported the preparation of partially exfoliated PC/clay nanocomposites using cyclic carbonate oligomers. It is well known $[24,25]$ that the migration of low molecular weight cyclic carbonate oligomers into the clay galleries favor the exfoliation of the clay and also in this case a partially exfoliated morphology was obtained. Suin and coworkers $[26,27]$ have recently reported a method to produce optically transparent polycarbonate nanocomposites by solvent casting and melt blending. The method uses a phosphonium modified montmorillonite that does not give rise to the degradation problems previously described in the literature. However, only low amounts of OM-clay have been used (0.5 and $1 \mathrm{wt} \%)$.

In order to solve the dispersion and color issues previously encountered in the in-situ preparation of PC/clay nanocomposites we have developed a method that involves a multiple level approach. It consists in both decreasing the PC degradation during the nanocomposite preparation (by decreasing the reaction temperature and using a more stable organic modifier of the clay) and in enhancing the compatibility between the clay and the polymer.
Activated carbonates, such as bis(methyl salicyl) carbonate (BMSC) can be used in order to decrease polymer degradation by lowering the reaction temperature below $270{ }^{\circ} \mathrm{C}$ and the residence time with respect to the traditional polycondensationprocess that use diphenyl carbonate (DPC) as carbonate groups source [28, 29]. Moreover, the equilibrium of the reaction between bisphenol A (BPA) and BMSC is shifted toward the formation of the products (94\%) while using DPC the reaction equilibrium is shifted towards the reagents and the continuous elimination of phenol is necessary to reach high conversion and high molecular weights. Recently, Kamps et al. [29] have reported the use of BMSC for the synthesis of differentiated polycarbonates resins via melt transcarbonation. The enhanced reactivity of BMSC over diphenyl carbonate permits to decrease reaction temperatures, thus allowing the use of monomers that could not be used with the standard melt polycondensation due to volatility and thermal stability issues. Several attempts have been performed in the past in order to increase the compatibility between the clay and the polymer in order to reach a better and more stable dispersion of the clay platelets in the polymer matrix. The increased compatibility can be achieved both by the modification of the clay and of the polymer. For example, ionic groups can be inserted in the polymer chain in order to increase the compatibility with the clay surface $[30,31]$. In particular, we have reported that the presence of sulfonated groups provides the thermodynamic driving force for the production of nanocomposites derived from montmorillonite clays [30]. Combining a poly(butylene terephthalate) (PBT) ionomer with montmorillonite clays results in exfoliation of the clays due to favorable electrostatic interactions between the charged surfaces of the silicate clay particles and the $-\mathrm{SO}_{3} \mathrm{Na}$ groups of the PBT-ionomer. Moreover, the presence of covalently bonded ionic groups along the polymer chain produces a consistent modification on the physical and rheological properties of polymers [32-35]. Indeed, ionomers (polymers containing less than $10 \mathrm{~mol} \%$ of ionic groups) have been shown to exhibit considerably higher moduli and higher glass transition temperatures compared to those of their non-ionic counterparts due to the formation of ionic aggregates [36]. Telechelic ionomers are polymers with ionic groups selectively located at the end of the polymer chains give rise only to electrostatic chain extension [37]. 
On the contrary, random ionomers (polymers with ionic groups randomly distributed along the polymer chain) give rise to a gel-like or cross-linked aggregation [37]. For this reason, telechelic ionomers can be prepared with lower melt viscosities and higher molecular weights with respect to random ionomers. For example, we have reported the synthesis of telechelic PBT ionomers, observing a higher thermal and hydrolytic stability and lower melt viscosity with respect to random ionomers [37].

Dow Chemicals has patented [38] a melt method for the synthesis of telechelic sulfonated PC by adding the phenylester of sulfobenzoic acid sodium salt at the beginning of the polycondensation of bisphenol A (BPA) and diphenylcarbonate. PC ionomers present a strong non-Newtonian melt rheology behavior along with increased solvent and flame resistance [38]. However, this method gives rise to a consistent amount of degradation products affording a dark yellow material completely insoluble in dichloromethane. The main reason of this insolubility can be ascribed to the cross-linking due to the formation of Fries rearrangement by-products due to the high temperature necessary for the polycondensation process.

We have recently reported a novel melt method to produce telechelic sulfonated PC ionomers [39] with high ionic content, low degradation and good color, using BMSC in order to reduce the reaction temperature and the residence time.

Regarding the clay modification, the general method to improve the compatibility the clay and the polymer consists in the modification of the clay with ammonium salts bearing long alkyl chains. This strategy has been used by Okada and Usuki in the first preparation of polymer/clay nanocomposites $[13,14]$ and used since then in a large number of publications. However, ammonium modified clays are not stable above $240^{\circ} \mathrm{C}$ and therefore are not suitable for the preparation of nanocomposites of polymers that have higher polymerization and processing temperatures. On the contrary, imidazolium salts possess a significantly higher thermal stability and have been used to modify clays, obtaining OM-MMTs with degradation temperatures that can exceed $350^{\circ} \mathrm{C}[40,41]$. In particular, imidazolium salts bearing two alkyl chains are particularly interesting since give rise to clays with a $d$-spacing above $25 \AA$ and with a thermal stability above $300^{\circ} \mathrm{C}$ [42]. Moreover, imidazolium cations are well known to impart antimicrobial properties to polymers [43, 44].

On the basis of these facts, we have developed a novel method that both reduces the degradation of the polymer matrix (using imidazolium clays and lower reaction temperatures, employing BMSC as activated carbonate) and increases the clay dispersion (by enhancing the polymer-clay interactions using telechelic ionomeric PC). In this paper we report for the first time an in-situ polymerization method to prepare PC nanocomposite with improved dispersion of the clay, thermal and optical properties with respect to the methods previously reported in the literature.

\section{Experimental section}

\subsection{Materials}

Sodium 3-sulfobenzoic acid (SBENa), sodium carbonate, bisphenol A, tetramethylammonium hydroxide (TMAH), imidazole, 1-bromohexadecane, sodium hydroxide, potassium hydroxide (all from Aldrich Chemicals) were high purity products and were not purified before use. Bis(methyl salicyl) carbonate was a gift from SABIC-IP.

Sodium montmorillonite (Dellite HPS) and organically modified MMT (Dellite $72 \mathrm{~T}$ ) were purchase by Laviosa Chimica Mineraria. Dellite HPS has a $d$ spacing of $12.9 \AA$, a Cation Exchange Capacity of $128 \mathrm{mmol} / 100 \mathrm{~g}$, a particle size of $6-8 \mu \mathrm{m}$ and loss on ignition of $6 \%$. Montmorillonite exchanged with an ammonium salt bearing two hydrogenated tallow chains and two methyl groups (Dellite $72 \mathrm{~T}$ ) has a $d$-spacing of $26.2 \AA$, a Cation Exchange Capacity of $128 \mathrm{mmol} / 100 \mathrm{~g}$, a particle size of $6-8 \mu \mathrm{m}$, and a loss on ignition of $36 \%$.

\subsection{Imidazolium synthesis}

\subsubsection{N-hexadecylimidazole synthesis}

Potassium hydroxide $8.415 \mathrm{~g}(0.150 \mathrm{~mol})$, was added to a solution containing $6.800 \mathrm{~g}(0.100 \mathrm{~mol})$ of imidazole in $200 \mathrm{~mL}$ of DMSO, the mixture was stirred for 30 minutes at $70^{\circ} \mathrm{C}$, and 1-bromohexadecane (32.060 g, $0.105 \mathrm{~mol})$ was added drop-wise under vigorous stirring (Figure 1). After a night the mixture was cooled to room temperature, $50 \mathrm{~mL}$ of distilled water were added, and the alkyl azole precipitated as a pale yellow solid. The salt was filtered and washed 4 times with $500 \mathrm{~mL}$ of distilled water. The product was then dried (yield $>95 \%$ ). 


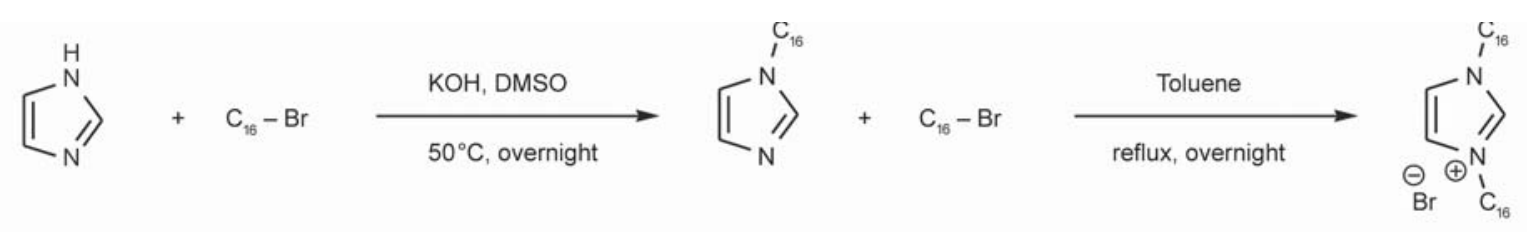

Figure 1. Preparation of di-alkyl imidazolium salt

\subsubsection{1,3-Di-hexadecylimidazolium bromide synthesis}

1-Bromohexadecane $(32.060 \mathrm{~g}, 0.105 \mathrm{~mol})$, was added drop-wise under vigorous stirring to a mixture of $0.1 \mathrm{~mol}$ of $\mathrm{N}$-hexadecylimidazole in $200 \mathrm{~mL}$ of anhydrous toluene (Figure 1). The mixture was stirred overnight at reflux temperature, and then the solvent was distilled off. The residue was washed 4 times with $100 \mathrm{~mL}$ of THF, the suspension was filtered and dried in a oven under reduced pressure (yield $>95 \%$ ).

\subsection{OM-clay preparation}

The preparation of dialkyl-imidazolium montmorillonite has been conducted by a cation-exchange reaction between the montmorillonite (Dellite HPS by Laviosa Chimica Mineraria) and an excess of dialkyl-imidazolium salt ( $40 \%$ with respect to the exchange capacity of the host). The salt was dissolved in methanol at $60^{\circ} \mathrm{C}$ and the resulting solution was added drop-wise to an aqueous suspension of montmorillonite $(1 \mathrm{wt} \%)$. The mixture was stirred for 5 hours at $60^{\circ} \mathrm{C}$. The imidazolium-exchanged montmorillonite was collected by filtration and washed with 1 liter of deionized water $(10 \times 100 \mathrm{~mL})$ to remove all residual anions. The product was then dried at room temperature and under vacuum at $100^{\circ} \mathrm{C}$ overnight, pulverized and washed 5 times with dichloromethane. The characterization of the modified clay was carried out by TGA and XRD analysis.

\subsection{Preparation of nanocomposite of sulfonated telechelic PC}

A round bottom wide-neck glass reactor $(250 \mathrm{~mL}$ capacity) was charged with BPA (25.30 g; $110.8 \mathrm{mmol})$, 3-SBENa (1.00 g; $3.32 \mathrm{mmol}$ ), the organically modified clay and the catalyst (a mixture of $2.22 \cdot 10^{-2} \mathrm{mmol}$ tetramethylammonium hydroxide and $8.43 \cdot 10^{-5} \mathrm{mmol}$ of $\mathrm{NaOH})$. The reactor was closed with a three-neck flat flange lid equipped with a mechanical stirrer and a torque meter. The system was then connected to a water cooled condenser and immersed in a thermostatic oil-bath at $210^{\circ} \mathrm{C}$ and the stirrer switched on at $100 \mathrm{rpm}$ after complete melting of the reactants.
After 90 minutes BMSC (36.95 g; 111.9 mmol) was then carefully added and dynamic vacuum was applied at 130 mbar for 10 minutes. The temperature was then increased to $260^{\circ} \mathrm{C}$ in 10 minutes and the pressure decreased to $0.2 \mathrm{mbar}$. The reaction melt was very viscous after 10 minutes from the application of dynamic vacuum and the stirring was very difficult and slow in the last part of the polymerization. The very viscous pale yellow and transparent melt was discharged from the reactor and analyzed by ${ }^{1} \mathrm{H}-\mathrm{NMR}$ (proton nuclear magnetic resonance), GPC (el permeation chromatography), DSC (differential scanning calorimetry) and TGA (thermogravimetric analysis). The polymerization was repeated without the addition of SBENa.

\subsection{Instrumental}

${ }^{1} \mathrm{H}-\mathrm{NMR}$ spectra were recorded with a Varian XL-400 spectrometer (chemical shifts are downfield from TMS), using hot deuterated DMSO as solvent. The spectra have been recorded just after dissolution in order to avoid the precipitation of the polymer.

Gel permeation chromatography (GPC) analysis was performed using a mixture of chloroform as eluent (elution rate of $0.3 \mathrm{~mL} / \mathrm{min}$ ) on a HP 1100 Series apparatus equipped with a PL Gel 5 Mini-Mixed-C column and a UV detector. Calibration was performed with polystyrene standards.

Differential scanning calorimetry (DSC) analysis was performed using a Perkin Elmer DSC6. The instrument was calibrated with high purity standards. Dry nitrogen was used as purge gas with a heating and cooling rate of $20^{\circ} \mathrm{C} / \mathrm{min}$. All transitions have been measured after a heating scan to $250^{\circ} \mathrm{C}$ and cooling down to room temperature in order to delete previous thermal history.

The thermogravimetric analyses (TGA) were performed using a Thermal Analysis Instruments model Q50 in nitrogen (gas flow: $40 \mathrm{~mL} / \mathrm{min}$ ) at $10^{\circ} \mathrm{C} / \mathrm{min}$ heating rate, from $60^{\circ} \mathrm{C}$ to $750^{\circ} \mathrm{C}$.

The Wide Angle X-ray Scattering (WAXS) data were collected with a X'PertPro diffractometer, equipped with a copper anode $\left(\mathrm{K}_{\alpha}\right.$ radiation, $\left.\lambda=1.5418 \AA\right)$. 
The data were collected in the $2 \theta$ range $5-60^{\circ}$ by means of an X'Celerator detector.

TEM analyses were performed using a JEOL JEM 2010 instrument at $200 \mathrm{kV}$ accelerating voltage and LaB6 filament. The samples were prepared by cryogenic ultra-microtoming.

The optical analysis was performed according to ASTM D1003 with A BIK-Gardener Haze-Gard I instrument.

Storage modulus was measured at $23^{\circ} \mathrm{C}$ by DMTA (dynamic mechanical thermoanalysis) analysis performed with a Rheometrics dynamic mechanic thermal analyzer DMTA 3E with a dual cantilever testing geometry.

\section{Results and discussion}

The clay used in the present work has been prepared by exchange with an imidazolium salt bearing two long alkyl chains. As reported in the introduction, imidazolium clays are more stable compared to standard clays modified with quaternary ammonium salts. Indeed, as reported in Figure 2, the imidazolium modified clay (D-2AI) is almost $100{ }^{\circ} \mathrm{C}$ more stable compared to a commercial clay exchanged with a quaternary ammonium salt (D-72 $\mathrm{T}$ from Laviosa Chimica Mineraria) obtaining an organically modified clay that is stable at temperature up to $300^{\circ} \mathrm{C}$. The imidazoilum salt has been modified with two C16 alkyl chains in order to increase the $d$-spacing of the clay, due to larger hydrodynamic volume of this saltwith respect to the imidazolium salts previously reported in the literature that only contain one long alkyl chain $[40,41]$. In this way a $d$-spacing of $31 \AA$ A has been obtained Figure 3 .

We have previously reported [39] that the one-pot reaction of BMSC, BPA and SBENa does not produce telechelic ionomers since the reaction mixture remains

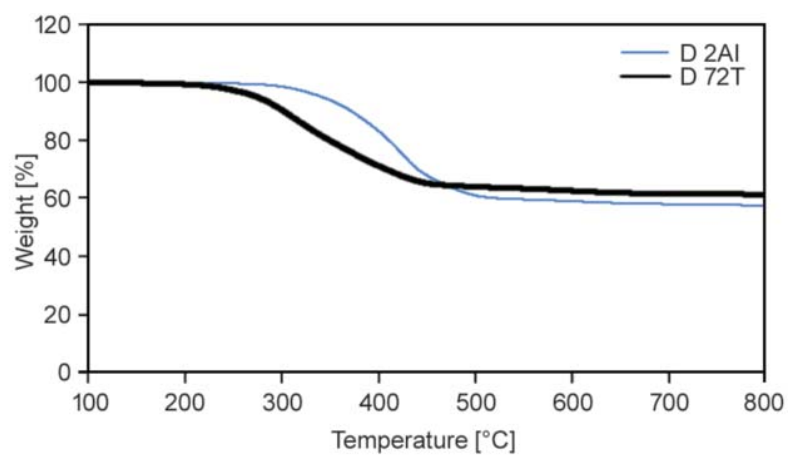

Figure 2. Thermal stability of quaternary ammonium (D-72 T) and imidazolium(D-2AI) modified montmorillonite

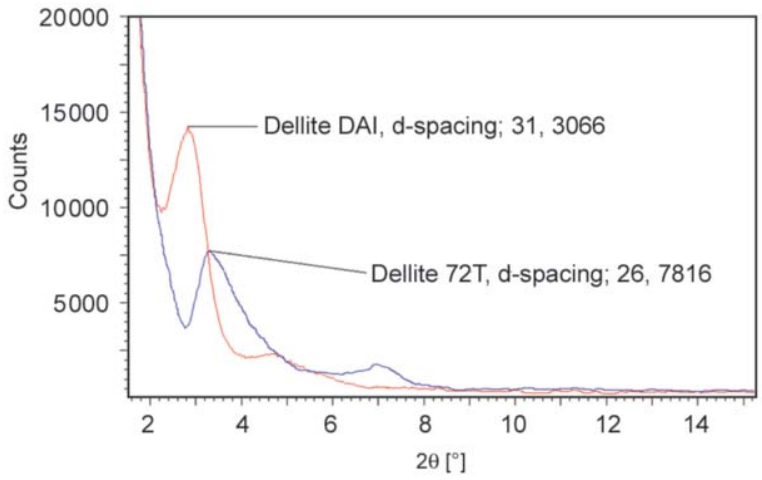

Figure 3. XRD of organically modified-modified montmorillonites

opaque and the SBENa can be mainly recovered unreacted at the end of the polymerization process. In order to improve the reaction of BMSC with BPA we have adopted an approach similar to that used for telechelic PBT synthesis. The method consists in pre-reacting the sulfobenzoic acid derivative with the diol in order to improve the solubility of the salt in the reaction mixture Figure 4. ${ }^{1} \mathrm{H}-\mathrm{NMR}$ analysis of samples taken during the first stage of polymerization has shown that the reaction of BMSC and BPA is consistently faster than the reaction of SBENa with BPA. Therefore, after a few minutes of reaction the amount of unreacted BPA drops consistently, thus decreasing the reaction rate with SBENa. For this reason, BPA and 3\% by mol of SBENa have been pre-reacted for 90 minutes at $210^{\circ} \mathrm{C}$ before the addition of BMSC. According to our previous work [39] a mixture of tetramethylammonium hydroxide and $\mathrm{NaOH}$ has been used as catalyst. The clay (3 wt $\%$ respect to the polymer) modified with a 1,3-di-hexadecylimidazolium salt (D-2AI) was added at the beginning of the pre-step. BMSC was then added and the vacuum was slowly applied down to 130 mbar. The temperature was then increased to $260^{\circ} \mathrm{C}$ while the vacuum decreased down to $0.1 \mathrm{mbar}$. The reaction melt became very viscous in a few minutes and the reaction was carried out at full vacuum for additional 30 minutes, affording a pale yellow and transparent material (NC-1). A nanocomposite of PC without the presence of ionic groups was also synthesized (NC-2) along with a ionomer with $3 \%$ of ionic telechelic groups (I-1) and a standard polycarbonate (PC), always using BMSC as activated carbonate and the same polymerization procedure used for the in-situ polymerization of the nanocomposites.

${ }^{1} \mathrm{H}-\mathrm{NMR}$ analysis of the nanocomposites Figure 5 shows that no significant degradation reaction takes 

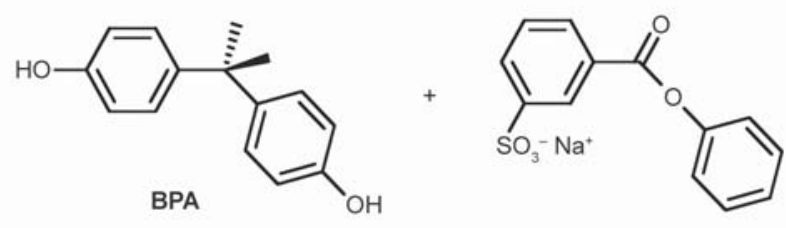

D-2AI

Na-MMT modified with

dihexadecylimidazolium (3 wt\%)

SBENa $(3 \%$ by mol)
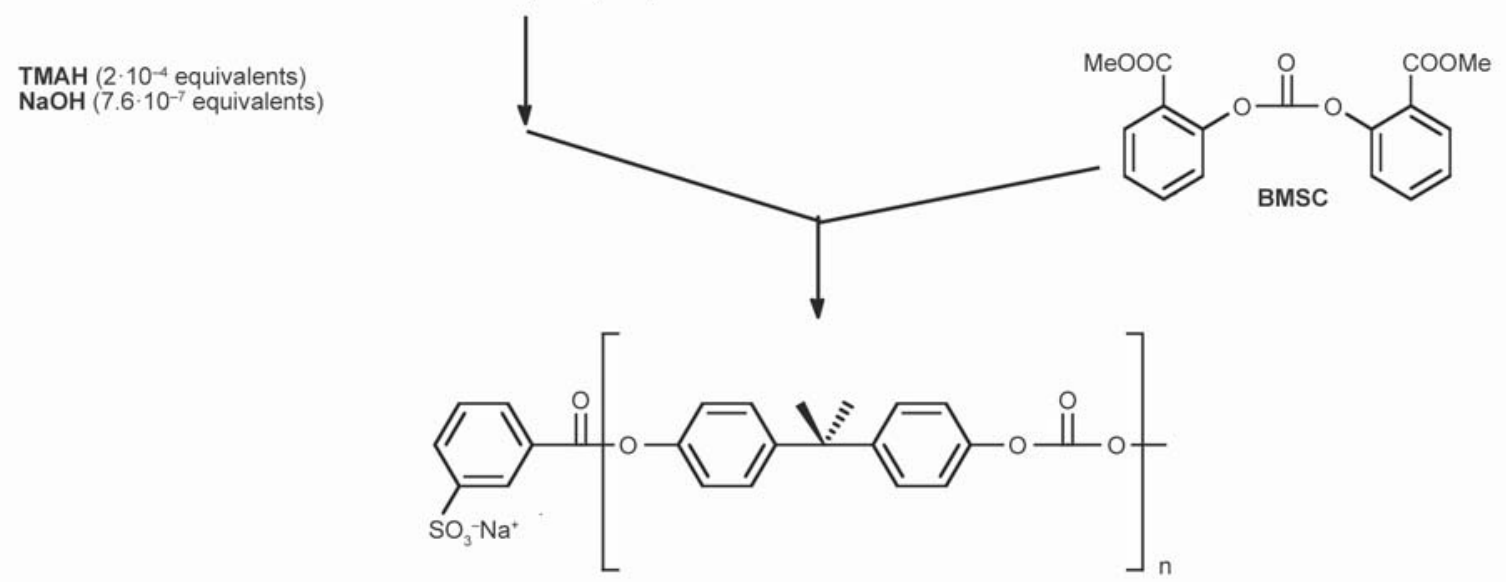

Figure 4. In-situ polymerization scheme

place, since no Fries by-products are detectable by NMR [39] and that the end-groups are mainly ionic. However, the NMR also shows that both $\mathrm{OH}$ and BMSC end-groups are still present in the final nanocomposite while in the case of the telechelic PC almost no trace of $\mathrm{OH}$ groups is present. Indeed, the molecular weight of the two nanocomposites (NC-1 and NC-2) is lower compared to those of the standard PC and of the ionomer I-1 Table 1. It is well known $[1,2]$, that the presence of clays increase the barrier properties of polymers and therefore this affects the removal of methyl salicylate from the reaction mixture decreasing the reaction rate and the molecular weight.

The clay dispersion was analyzed by TEM Figure 6 and XRD Figure 7 analyses. The micrographs in

Table 1. Molecular weight of telechelic PC and nanocomposites

\begin{tabular}{|l|c|c|c|c|}
\hline $\begin{array}{c}\text { Sample } \\
\text { name }\end{array}$ & Clay & $\begin{array}{c}\text { Ionic } \\
\text { content }\end{array}$ & $\boldsymbol{M}_{\mathbf{w}}$ & $\boldsymbol{M}_{\mathbf{n}}$ \\
\hline $\mathrm{PC}$ & - & - & 50000 & 22300 \\
\hline $\mathrm{I}-1$ & - & $3 \%$ & 44000 & 20100 \\
\hline $\mathrm{NC}-1$ & $3 \% \mathrm{w} / \mathrm{w} \mathrm{D}-2 \mathrm{AI}$ & $3 \%$ & 31400 & 14300 \\
\hline $\mathrm{NC}-2$ & $3 \% \mathrm{w} / \mathrm{w} \mathrm{D}-2 \mathrm{AI}$ & - & 32800 & 14800 \\
\hline
\end{tabular}

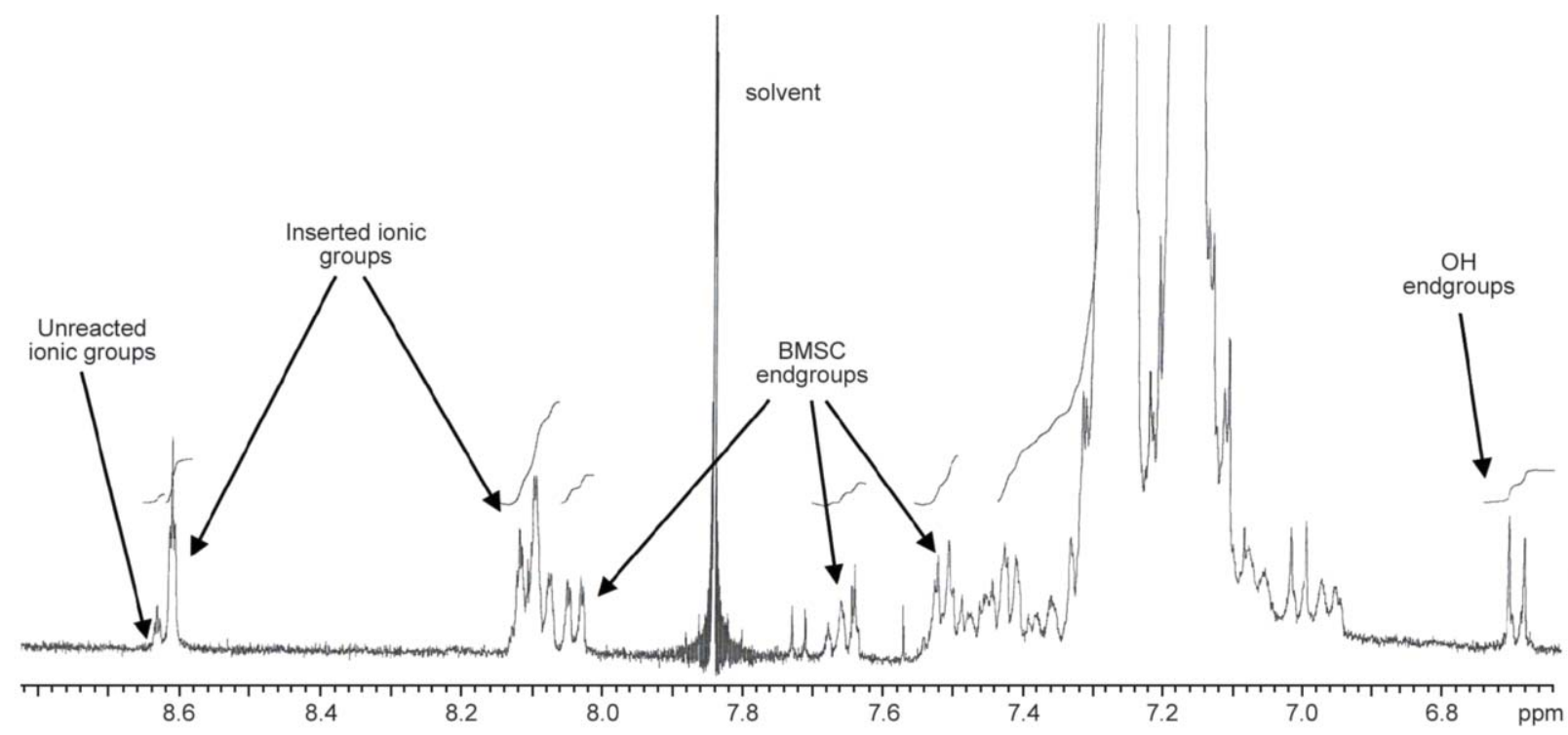

Figure 5. ${ }^{1} \mathrm{H}-\mathrm{NMR}$ in $\mathrm{DMSO} / \mathrm{CDCl} 3(30 / 70 \mathrm{v} / \mathrm{v})$ of the nanocomposite of telechelic polycarbonate $(\mathrm{NC}-1)$ 


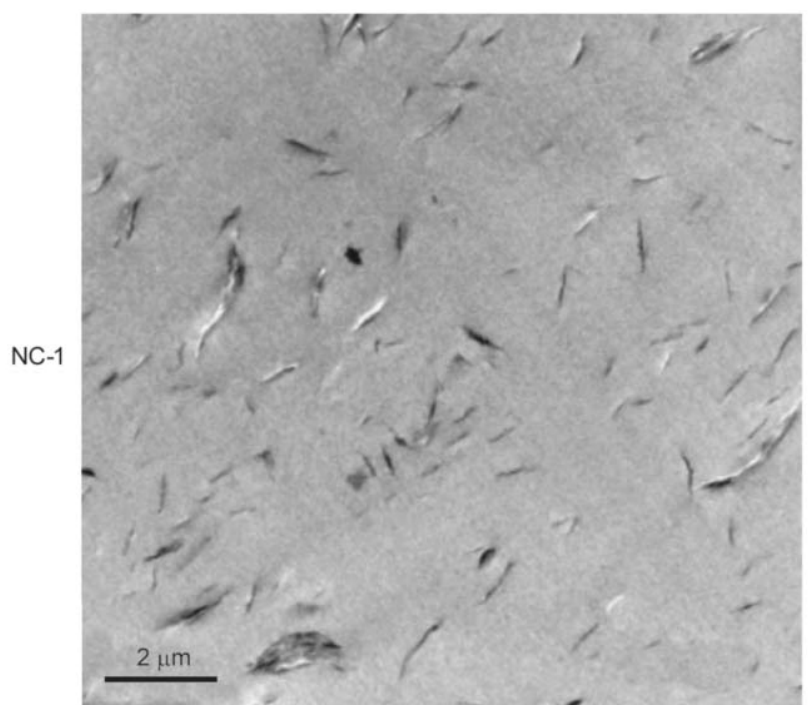

a)

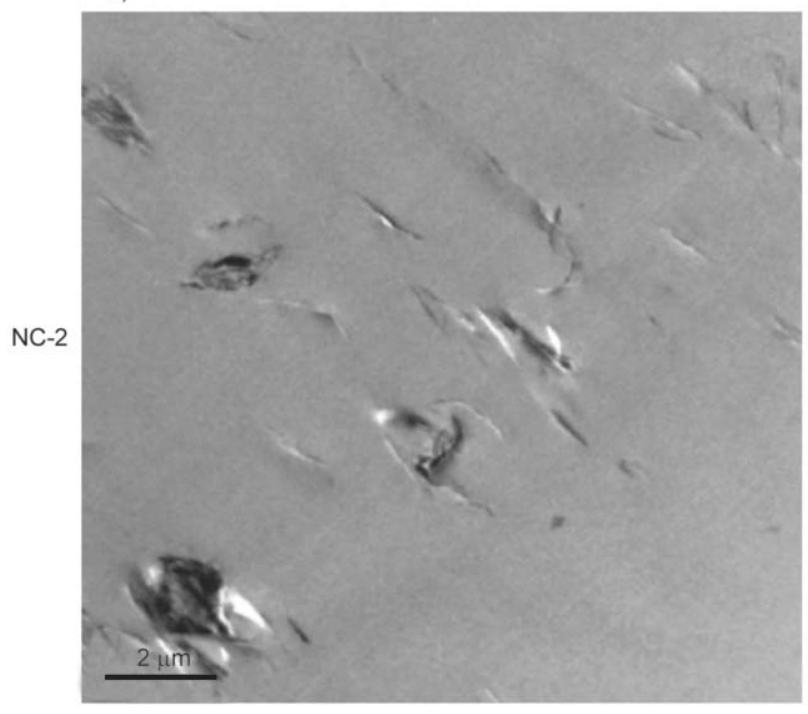

c)

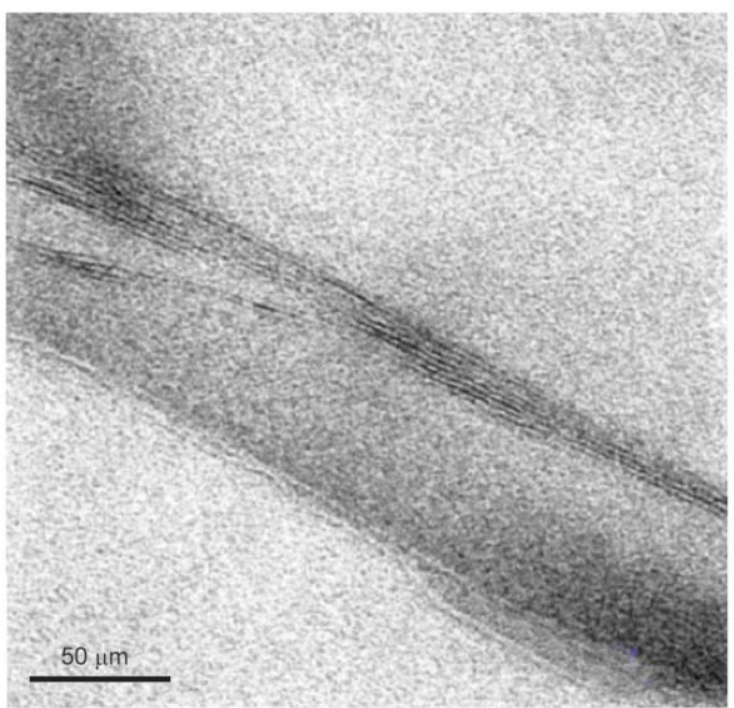

b)

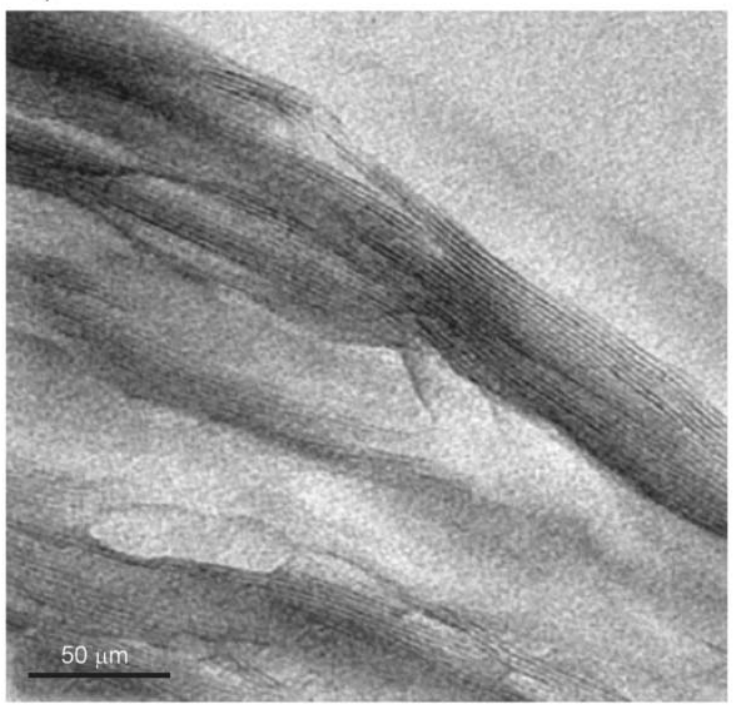

d)

Figure 6. TEM micrographs of nanocomposites of a) ionomeric PC (NC-1) and b) of PC (NC-2) at c) 5800 and d) 310000 magnifications

Figure 6. clearly show a better degree of dispersion of the clay when ionic groups are used, even if some intercalated clay particles are clearly present for NC-1. The XRD analysis Figure 7 show no reflections for the nanocomposite obtained using ionic groups (NC-1), while a reflection corresponding to a $d$-spacing of $34.3 \AA$ is present for the nanocomposite prepared without the use of ionic groups, indicating again the positive effect of ionic moieties on clay dispersion. The images of $1 \mathrm{~mm}$ thick plates of the nanocomposites Figure 8 clearly show, in agreement with the TEM and XRD results, more opacity for the nanocomposite that do not have ionic end-groups, again indicating the positive effect of the ionic groups on the clay dispersion. The optical analysis (measured according to ASTM D1003) of the plates indicates a Transmission of $86 \%$ and a Haze of $11 \%$ for NC-1

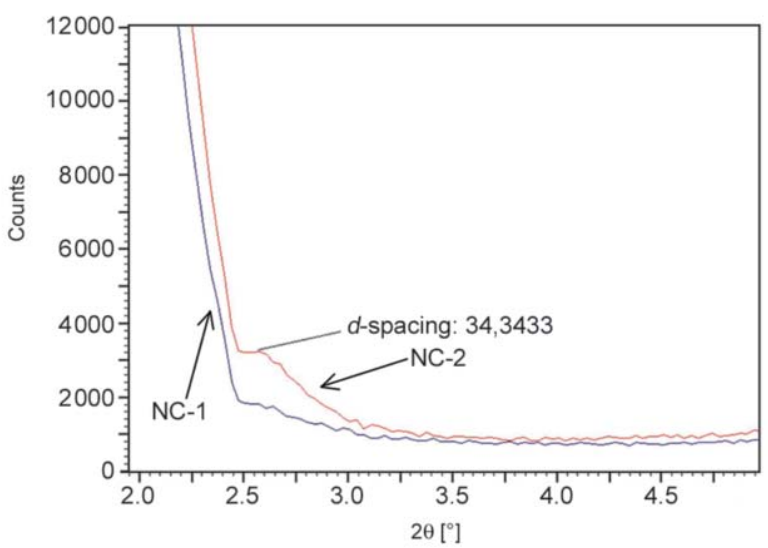

Figure 7. XRD of nanocomposites of telechelic PC (NC-2) and standard PC (NC-1)

while a lower Transmission (80\%) and higher Haze (25\%) where measured for NC-2. Moreover, the nanocomposite obtained using BMSC and imidazolium 


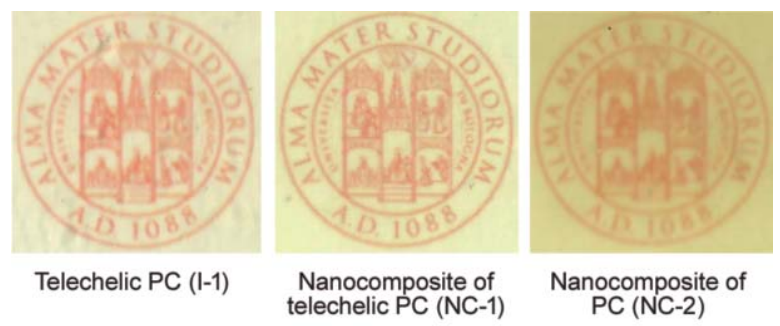

Figure 8. Images of $1 \mathrm{~mm}$ thick films of telechelic PC and nanocomposites

Table 2. Thermal and mechanical properties of PC nanocomposites

\begin{tabular}{|l|c|c|c|c|}
\hline $\begin{array}{c}\text { Sample } \\
\text { name }\end{array}$ & $\begin{array}{c}\boldsymbol{T}_{\mathbf{g}} \\
{\left[{ }^{\circ} \mathbf{C}\right]}\end{array}$ & $\begin{array}{c}\text { Onset } \\
\text { degradation } \\
\text { temperature }\end{array}$ & $\begin{array}{c}\mathbf{1 0 \%} \\
\text { degradation } \\
\text { temperature }\end{array}$ & $\begin{array}{c}\text { Storage } \\
\text { modulus at 23 } \\
\text { [GPa] }\end{array}$ \\
\hline $\mathrm{PC}$ & 148 & $430^{\circ} \mathrm{C}$ & $469^{\circ} \mathrm{C}$ & 1.21 \\
\hline $\mathrm{I}-1$ & 147 & $409^{\circ} \mathrm{C}$ & $450^{\circ} \mathrm{C}$ & 1.09 \\
\hline sNC-1 & 142 & $445^{\circ} \mathrm{C}$ & $475^{\circ} \mathrm{C}$ & 1.31 \\
\hline $\mathrm{NC}-2$ & 145 & $449^{\circ} \mathrm{C}$ & $482^{\circ} \mathrm{C}$ & 1.28 \\
\hline
\end{tabular}

modified clay is pale yellow even if no gas purge was used during the polymerization, indicating that the use of this new approach permits to obtain PC nanocomposites by in-situ polymerization that are not dark colored as those previously reported in the literature [22].

The TGA analysis Table 2 show a consistently higher thermal stability for the nanocomposite with respect to the telechelic ionomeric PC, the nanocomposite with ionic groups being slightly less stable with respect to that without the ionic groups. No significant differences were observed in DSC analyses. The glass transition temperatures $\left(T_{\mathrm{g}}\right)$ were all in the range $142-148^{\circ} \mathrm{C}$ and no evidence of crystallinity was found for all samples. DMTA analysis has shown a slightly higher storage modulus for the nanocomposites with respect to standard PC and PC-ionomer. The detailed study of the mechanical properties and the effect of different amounts of ionic groups will be reported in a following paper.

\section{Conclusions}

Nanocomposites of PC with imidazolium modified clays with good color and clay dispersion have been prepared by in-situ polymerization using BMSC as activate carbonate. In this way, the lower reaction temperature and shorter polymerization time consistently decrease the degradation reactions observed using other methods. The addition of ionic groups at the end of the polymer chain increases the interaction between the clay surface and the polymer producing a better dispersion of the clay. The presence of the clay permits to increase the thermal stability of PC.

\section{References}

[1] Alexandre M., Dubois P.: Polymer-layered silicate nanocomposites: Preparation, properties and uses of a new class of materials. Materials Science and Engineering R: Reports, 28, 1-63 (2000). https://doi.org/10.1016/S0927-796X(00)00012-7

[2] Sinha Ray S., Okamoto M.: Polymer/layered silicate nanocomposites: A review from preparation to processing. Progress in Polymer Science, 28, 1539-1641 (2003). https://doi.org/10.1016/j.progpolymsci.2003.08.002

[3] Liu L., Qi Z., Zhu X.: Studies on nylon 6/clay nanocomposites by melt-intercalation process. Journal of Applied Polymer Science, 71, 1133-1138 (1999).

https://doi.org/10.1002/(SICI)10974628(19990214)71:7<1133::AID-APP11>3.0.CO;2-N

[4] Messersmith P. B., Giannelis E. P.: Synthesis and barrier properties of poly( $\varepsilon$-caprolactone)-layered silicate nanocomposites. Journal of Polymer Science Part A: Polymer Chemistry, 33, 1047-1057 (1995). https://doi.org/10.1002/pola.1995.080330707

[5] Sullalti S., Colonna M., Berti C., Fiorini M., Karanam S.: Effect of phosphorus based flame retardants on UL94 and comparative tracking index properties of poly(butylene terephthalate). Polymer Degradation and Stability, 97, 566-572 (2012).

https://doi.org/10.1016/j.polymdegradstab.2012.01.015

[6] Acquasanta F., Berti C., Colonna M., Fiorini M., Karanam S.: Study of glow wire ignition temperature (GWIT) and comparative tracking index (CTI) performances of engineering thermoplastics and correlation with material properties. Polymer Degradation and Stability, 96, 566-573 (2011).

https://doi.org/10.1016/j.polymdegradstab.2010.12.024

[7] Yano K., Usuki A., Okada A., Kurauchi T.: Synthesis and properties of polyimide-clay hybrid films. Journal of Polymer Science Part A: Polymer Chemistry, 31, 2289-2294 (1993).

https://doi.org/10.1002/(SICI)10990518(199708)35:11<2289::AID-POLA20>3.0.CO;2-9

[8] Okada A., Usuki A.: The chemistry of polymer-clay hybrids. Materials Science and Engineering: C, 3, 109115 (1995).

https://doi.org/10.1016/0928-4931(95)00110-7

[9] Pavlidou S., Papaspyrides C. D.: A review on polymerlayered silicate nanocomposites. Progress in Polymer Science, 33, 1119-1198 (2008).

https://doi.org/10.1016/j.progpolymsci.2008.07.008

[10] Giannelis E. P.: Polymer-layered silicate nanocomposites: Synthesis, properties and applications. Applied Organometalic Chemistry, 12, 675-680 (1998).

https://doi.org/10.1002/(SICI)10990739(199810/11)12:10/11<675::AID-AOC779>3.0.CO;2-V 
[11] Morgan B., Harris J. D.: Exfoliated polystyrene-clay nanocomposites synthesized by solvent blending with sonication. Polymer, 45, 8695-8703 (2004).

https://doi.org/10.1016/j.polymer.2004.10.067

[12] Hussain F., Hojjati M., Okamoto M., Gorga R. E.: Review article: Polymer-matrix nanocomposites, processing, manufacturing, and application: An overview. Journal of Composite Materials, 40, 1511-1575 (2006). https://doi.org/10.1177/0021998306067321

[13] Usuki A., Kojima Y., Kawasumi M., Okada A., Fukushima Y., Kurauchi T., Kamigaito O.: Synthesis of nylon 6-clay hybrid. Journal of Materials Research, 8, 1179-1184 (1993).

https://doi.org/10.1557/JMR.1993.1179

[14] Kojima Y., Usuki A., Kawasumi M., Okada A., Fukushima Y., Kurauchi T., Kamigaito O.: Mechanical properties of nylon 6-clay hybrid. Journal of Materials Research, 8, 1185-1189 (1993).

https://doi.org/10.1557/JMR.1993.1185

[15] Yoon P. J., Hunter D. L., Paul D. R.: Polycarbonate nanocomposites. Part 1. Effect of organoclay structure on morphology and properties. Polymer, 44, 5323-5339 (2003). https://doi.org/10.1016/S0032-3861(03)00528-7

[16] Xie W., Gao Z., Pan W-P., Hunter D., Singh A., Vaia R.: Thermal degradation chemistry of alkyl quaternary ammonium montmorillonite. Chemistry of Materials, 13, 2979-2990 (2001).

https://doi.org/10.1021/cm010305s

[17] Feng J., Hao J., Du J., Yang R.: Using TGA/FTIR TGA/MS and cone calorimetry to understand thermal degradation and flame retardancy mechanism of polycarbonate filled with solid bisphenol A bis(diphenyl phosphate) and montmorillonite. Polymer Degradation and Stability, 97, 605-614 (2012).

https://doi.org/10.1016/j.polymdegradstab.2012.01.011

[18] Christopher W. F., Fox D. W.: Polycarbonates. Reinhold Publishing, New York (1962).

[19] Legrand D. G., Bendler J. T.: Handbook of polycarbonate science and technology. Marcel Dekker, New York (2000).

[20] Colonna M., Fiorini M.: Solid state polymerization of bisphenol A polycarbonate: Effect of the crystallization method and polymerization conditions. Polymer Engineering and Science, 55, 1024-1029 (2015).

https://doi.org/10.1002/pen.23971

[21] Brunelle D. J.: Advances in polycarbonates: An overview. in 'Advances in polycarbonates' (eds.: Brunelle D. J., Korn M. R.) ACS Symposium Series, Washington, 1-5 (2005).

https://doi.org/10.1021/bk-2005-0898.ch001

[22] Rama M. S., Swaminathan S.: Polycarbonate/clay nanocomposites via in situ melt polycondensation. Industrial and Engineering Chemistry Research, 49, 2217-2227 (2010).

https://doi.org/10.1021/ie9015649
[23] Huang X., Lewis S., Brittain W. J., Vaia R. A.: Synthesis of polycarbonate-layered silicate nanocomposites via cyclic oligomers. Macromolecules, 33, 2000-2004 (2000).

https://doi.org/10.1021/ma991709x

[24] Berti C., Binassi E., Colonna M., Fiorini M., Zuccheri T., Karanam S., Brunelle J. D.: Improved dispersion of clay platelets in poly(butylene terephthalate) nanocomposite by ring-opening polymerization of cyclic oligomers: Effect of the processing conditions and comparison with nanocomposites obtained by melt intercalation. Journal of Applied Polymer Science, 114, 3211-3217 (2009). https://doi.org/10.1002/app.30957

[25] Lee S-S., Ma Y. T., Rhee H-W., Kim J.: Exfoliation of layered silicate facilitated by ring-opening reaction of cyclic oligomers in PET-clay nanocomposites. Polymer, 46, 2201-2210 (2005).

https://doi.org/10.1016/j.polymer.2005.01.006

[26] Suin S., Khatua B. B.: Exfoliated and optically transparent polycarbonate/clay nanocomposites using phosphonium modified organoclay: Preparation and characterizations. Industrial and Engineering Chemistry Research, 51, 15096-15108 (2012).

https://doi.org/10.1021/ie302209x

[27] Suin S., Shrivastava N. K., Maiti S., Khatua B. B.: Optically transparent polycarbonate/clay nanocomposites with improved performance using phosphonium modified organoclay: Preparation and characterizations. Polymer Composites, 37, 199-212 (2016). https://doi.org/10.1002/pc.23171

[28] Brunelle D. J.: (Ortho-alkoxycarbonyaryl)-carbonate transesterification. U.S. Patent 4323668, USA (1982).

[29] Kamps J. H., Hoeks T., Kung E., Lens J. P., McCloskey P. J., Noordover B. A. J., Heuts J. P. A.: Activated carbonates: Enabling the synthesis of differentiated polycarbonate resins via melt transcarbonation. Polymer Chemistry, 7, 5294-5303 (2016). https://doi.org/10.1039/C6PY00925E

[30] Colonna M., Berti C., Binassi E., Fiorini M., Karanam S., Brunelle D. J.: Nanocomposite of montmorillonite with telechelic sulfonated poly(butylene terephthalate): Effect of ionic groups on clay dispersion, mechanical and thermal properties. European Polymer Journal, 46, 918-927 (2010). https://doi.org/10.1016/j.eurpolymj.2010.02.003

[31] Chisholm B. J., Moore R. B., Barber G., Khouri F., Hempstead A., Larsen M., Olson E., Kelley J., Balch G., Caraher J.: Nanocomposites derived from sulfonated poly(butylene terephthalate). Macromolecules, 35, 5508-5516 (2002). https://doi.org/10.1021/ma012224n

[32] Berti C., Celli A., Colonna M., Fiorini M., Marianucci E.: Modification of PET by reactive blending with sulfonated esters. II. Isothermal crystallization kinetics of PET-ionomers. Journal of Macromolecular Science Part B: Physics, 42, 989-1005 (2003). https://doi.org/10.1081/MB-120023553 
[33] Berti C., Celli A., Colonna M., Fabbri P., Fiorini M., Marianucci E.: Modification of PET by reactive blending with sulfonated esters, 1 . Synthesis and characterization of PET-ionomers. Macromolecular Symposia, 176, 211-222 (2001).

https://doi.org/10.1002/1521-3900(200112)176:1<211::AIDMASY211>3.0.CO;2-H

[34] Colonna M., Berti C., Binassi E., Fiorini M., Sullalti S., Acquasanta F., Vannini M., Di Gioia D., Aloisio I., Karanam S., Brunelle D. J.: Synthesis and characterization of imidazolium telechelic poly (butylene terephthalate) for antimicrobial applications. Reactive and Functional Polymers, 72, 133-141 (2012).

https://doi.org/10.1016/j.reactfunctpolym.2011.12.003

[35] Eisenberg A., King M.: Ion-containing polymers. Academic Press, New York (1977).

[36] MacKnight W. J., Earnest T. R.: The structure and properties of ionomers. Journal of Polymer Science: Macromolecular Reviews, 16, 41-120 (1981). https://doi.org/10.1002/pol.1981.230160102

[37] Berti C., Colonna M., Binassi E., Fiorini M., Karanam S., Brunelle D. J.: Telechelic ionomeric poly(butylene terephthalate): Synthesis, characterization and comparison with random ionomers. Reactive and Functional Polymers, 70, 366-375 (2010).

https://doi.org/10.1016/j.reactfunctpolym.2010.02.011

[38] Drumright R. E., Mullins M. J., Bales S. E.: Polycarbonate terminated by an ionic sulfonated aromatic moiety and preparation thereof. U.S. Patent 5644017, USA (1997).

[39] Colonna M., Berti C., Binassi E., Fiorini M., Sullalti S., Acquasanta F., Karanam S., Brunelle D. J.: Synthesis and characterization of sulfonated telechelic bisphenol A polycarbonate ionomers. Reactive and Functional Polymers, 71, 1001-1007 (2011).

https://doi.org/10.1016/j.reactfunctpolym.2011.07.002
[40] Gilman J. W., Awad W. H., Davis R. D., Shields J., Harris R. H., Davis C., Morgan A. B., Sutto T. E., Callahan J., Trulove P. C., DeLong H. C.: Polymer/layered silicate nanocomposites from thermally stable trialkylimidazolium-treated montmorillonite. Chemistry of Materials, 14, 3776-3785 (2002). https://doi.org/10.1021/cm011532x

[41] Cui L., Bara J. E., Brun Y., Yoo Y., Yoon P. J., Paul D. R.: Polyamide- and polycarbonate-based nanocomposites prepared from thermally stable imidazolium organoclay. Polymer, 50, 2492-2502 (2009). https://doi.org/10.1016/j.polymer.2009.03.036

[42] Karanam S., Berti C., Binassi E., Brunelle D. J., Colonna M., Fiorini M.: Process for synthesis of imidazolium and benzimidazolium surfactants and their use in clays and nanocomposites. U.S. Patent 20100056693, USA (2010).

[43] Colonna M., Berti C., Binassi E., Fiorini M., Sullalti S., Acquasanta F., Vannini M., Di Gioia D., Aloisio I.: Imidazolium poly(butylene terephthalate) ionomers with long-term antimicrobial activity. Polymer, 53, 1823 1830 (2012). https://doi.org/10.1016/j.polymer.2012.03.003

[44] Izmaylov B., Di Gioia D., Markova G., Aloisio I., Colonna M., Vasnev V.: Imidazolium salts grafted on cotton fibres for long-term antimicrobial activity. Reactive and Functional Polymers, 87, 22-28 (2015). https://doi.org/10.1016/j.reactfunctpolym.2014.12.007 